\title{
INTRODUCTION: TRADITIONAL VS. MODERN LEGAL SYSTEMS
}

\author{
By James C. N. Paul
}

The core of the papers in this issue were discussed by a panel at the World Congress of the International Sociological Association (ISA) in Uppsala in 1978. The group was organized by Professor Masaji Chiba (of Japan) in response to a request from the ISA's Research Committee on Sociology of Law, which asked for a session on "traditional vs. modern legal systems". Earlier discussions on the "modernization" of law in non-Western countries had suggested the importance of examining the concepts, approaches and assumptions which scholar's have used to study the interaction of "modern" legal structures with "traditional" ones. Of course this is not a new subject. Methodological problems have been raised by many scholars, for example, by Paul Bohannan's insistence on distinguishing between folk systems and analytical systems to criticize Max Gluckman's method and by those who have objected to approaches and assumptions followed in literature on "law and development". A review of methodological problems seemed appropriate in a forum of persons interested in socio-legal theory, development and comparative study of law in "third world" polities. Accordingly, Professor Chiba encouraged participants to focus attention on basic questions relating to choice of method.

The seven papers presented at Uppsala have been divided for purposes of publication into two groups. The first group included papers by Franco Lombardi, Peter G. Sack, Masaji Chiba and myself. These papers are reviews and critiques of approaches found in earlier Western, mainly American, literature on "law and modernization" or "law and development". They will be published in a forthcoming edition of Law and Development, a journal of the University of the Philippines Law Center. The second group, those by Upendra Baxi, Lakshman Marasinghe and Sandra B. Burman, present case studies, but they, too, are designed to illustrate the significance of choice of approach, and they are presented, in edited form, in this journal.

The papers from the Uppsala Conference have been supplemented by valuable additional material illustrative of the problems which Professor Chiba sought to expose at Uppsala. The article by van Rouveroy van Nieuwaal on "Unité du Droit ou Diversité du Droit" is another case study on the clash between "traditional (endogenous) and "modern" (imported) law. The review-essay by Brun-Otto Bryde on Volkmar Gessner's book "Recht und Konflikt" reviews one of the methodologically most ambitious attempts to "map" the legal system of a developing country (Mexico). It emphasizes the danger of using the "modern"-"traditional" dichotomy, and points to the Latin American example as a possible future for "modernized" legal cultures in which the "modern" law has succeeded in destroying "traditional" law without providing an alternative for the mass of the population who become "law-less". The interactions between "modern" law and the traditional structures which ithas often displaced have of course been a central concern in much writing about law in Asia and Africa. The Uppsala panel debated ways in which scholars and researchers can study these interactions: what phenomena should be examined? And why?

There are many contrasting approaches. At the risk of oversimplification three are briefly summarized here in the hope that this will indicate the significance of problems of method, and some issues and themes debated in the panel.

First, there are the "law and development" approaches, primarily propagated by North American scholars during the ' 60 s. These of ten started with the assumption that moderniza- 
tion of law was not only inevitable, as an aspect of social modernization, but it was a necessary occurrence in order to put the state under law and at the same time enable it to use law instrumentally to unify and develop society. Thus many "law and development" lawyers put priority on the problems of integrating legal systems, professionalizing grass roots justice, unifying legal process, using law to reform land tenure, family institutions and other social phenomena which seemed "backward", inconsistent with the goals of development, using law to create new state and private structures which would facilitate innovative economic activity, rational administration, rule of law and so forth.

A second approach started with very different assumptions, much more sympathetic to endogenous law. Scholars following it have of ten attempted to show how customary structures reflected basic cultural values and needs of rural or nomadic people, how they related to social and economic relations of relatively self-sufficient societies unaffected by the political economy of colonialism, how the introduction of "modern", professionalized institutions, procedures, rules and actors can produce access barriers to and alienation from the new structures which replace old ones. Thus, the regressive and oppressive side of "modern" law is often stressed in this literature.

Yet the problems of modernization will hardly go away, and the clock can hardly be turned back. The modern state will not wither. Police, local courts and administration 'and state bureaucracies operating in rural areas are not about to disappear. Social changes are taking place with rapidity in these communities: the penetration of mass communication, increasing linkages with urban societies, commercialization of agriculture, the creation of markets in land and tenancies and landless workers, the increasing presence of the state and increasing dependence of people on state and parastatal agencies for access to resources essential to human needs (schools, credit, seeds, technology, water resources, transport, markets, security); the growing impoverishment of masses of rural people who lack access to resources; the increasing social stratification of rural societies as a result of differential access to institutions which control or allocate vital resources (e.g., agricultural services). To varying extents these conditions are facts of life. The "social gaps" within countries have become a central concern in much of the current writing about development.

Thus, a third approach is to view the legal order which now exists from the perspective of impoverished rural people. This approach shifts attention from the usual efforts to depict modern vs. traditional law as a dichotomy - an effort which often suggests people must somehow choose between the two kinds of law.

Basic alternative human-needs-centered approaches to development emphasize, among other things, the need for mobilization and organization of the rural poor in order to develop stronger capacities to gain access and influence in local administration. These approaches emphasize the importance of finding ways to encourage "bottom up" responses to the problems created by top-down, centralized, bureaucratic and professionalized strategies of development. How can people use law - both in modern and endogenous forms - to articulate and advance their interests and secure resources (such as land, credit, knowledge, health care) essential to their needs? These approaches may emphasize the use of tradition to create alternative non-state structures (like the Rangpur "peoples' court" described by Baxi) as one kind of response. They may also emphasize the generation of group legal resources to cope with state structures as another strategy, e.g., the use of provisions of state law as a basis for group demands designed to force bureaucracies to heed the needs of the poor. Perhaps this kind of approach will increasingly be reflected in the next round of writing about law modernization and development. 